$10-2013$

\title{
Minority Stress Theory: An Examination of Factors Surrounding Sexual Risk Behavior Among Gay and Bisexual Men Who Use Club Drugs
}

Michael P. Dentato

Loyola University Chicago, mdentato@luc.edu

Perry N. Halkitis

New York University, perry.halkitis@nyu.edu

John Orwat

Loyola University Chicago, School of Social Work, jorwat@luc.edu

Follow this and additional works at: https://ecommons.luc.edu/socialwork_facpubs

Part of the Social Work Commons

\section{Author Manuscript}

This is a pre-publication author manuscript of the final, published article.

\section{Recommended Citation}

Dentato, M.P., Halkitis, P.N. \& Orwat, J. (2013). "Minority stress theory: An examination of factors surrounding sexual risk behavior among gay and bisexual men who use club drugs." Journal of Gay \& Lesbian Social Services, 25(4), 509-525, doi:10.1080/10538720.2013.829395

This Article is brought to you for free and open access by the Faculty Publications and Other Works by Department at Loyola eCommons. It has been accepted for inclusion in Social Work: School of Social Work Faculty Publications and Other Works by an authorized administrator of Loyola eCommons. For more information, please contact ecommons@luc.edu.

\section{c) (†) $\ominus$}

This work is licensed under a Creative Commons Attribution-Noncommercial-No Derivative Works 3.0 License. (c) 2013 Taylor \& Francis. 
$\underline{\text { Title }}$

Minority Stress Theory: An Examination of Factors Surrounding Sexual Risk Behavior among Gay \& Bisexual Men Who Use Club Drugs

$\underline{\text { Authors }}$

Michael P. Dentato, Ph.D.

Assistant Professor

Loyola University Chicago, School of Social Work

820 North Michigan Avenue, $12^{\text {th }}$ floor

Chicago, IL 60611

312.915.7030 phone

312.915.7645 fax

mdentato@luc.edu

Perry N. Halkitis, Ph.D., M.S., M.P.H.

Associate Dean for Research and Doctoral Studies

Professor of Applied Psychology, Public Health \& Medicine

New York University

Steinhardt School of Culture, Education \& Human Development

Director, Center for Health, Identity, Behavior \& Prevention Studies

John Orwat, Ph.D.

Associate Professor

Loyola University Chicago, School of Social Work

Acknowledgements

This research was supported by the National Institute on Drug Abuse Grant R01 DA13798 awarded to Perry N. Halkitis, Ph.D., M.S., M.P.H. 
$\underline{\text { Introduction }}$

Gay and bisexual men have a greater likelihood than the general population (Cochran, Mays \& Sullivan, 2003) for risk taking behaviors that include poly-substance use (KashubeckWest \& Szymanski, 2008; Kalichman \& Cain, 2004) and anonymous sex with multiple partners (Bimbi, Nanin, Parsons et al., 2006) that increases the risk for sexually transmitted infections (Halkitis, Zade, Shrem et al., 2004) such as HIV/AIDS (Halkitis, Green \& Carragher, 2006; Halkitis, Green \& Mourgues, 2005). Centers for Disease Control surveillance reports specifically evidence an alarming increase of new HIV infections among 13-24 year old men who have sex with other men (MSM) (CDC, 2010b). Notably, recent studies demonstrate a strong positive correlation between drug use and sexual risk behavior with casual partners with an HIV serostatus either unknown or serodiscordant (Mustanski, Newcomb, Du Bois et al., 2011). The identification of the factors associated with risk taking behaviors is important for ongoing education, the design and delivery of prevention programs, and treatment interventions. Previous studies have examined these factors from perspectives such as cognitive stress theory (Halkitis, et al. 2005; McKirnan, Ostrow \& Hope, 1996; Weinstein, 1993); minority stress theory (Hamilton \& Mahalik, 2009; Meyer, Schwartz \& Frost, 2008), individual level determinants of behavior (Jerome, Halkitis \& Siconolfi, 2009; Kashubeck-West \& Syzmanski, 2008; Crocker, Major \& Steele, 1998), and social causation associated with stigma, prejudice and related factors (Meyer, 2003; Link \& Phelan, 2006). This study examines risk taking behavior among gay and bisexual men from the perspective of minority stress theory.

Minority stress theory (MST) proposes that health disparities among populations such as men who have sex with men (MSM) can be explained in large part by stressors induced by a hostile, homophobic culture, which often results in experiences of external prejudice, 
expectations of rejection, and internalized homophobia (Meyer, 2003; Marshal et al., 2008) and may impact behavior and access to care. External prejudice refers to any perceived or actual experiences by an individual with either structural or institutional associations (i.e. policy) or related to direct social prejudice (i.e. hearing hateful language) (Meyer, 1995). The second MST concept relates to a person's expectation that they will experience rejection based on their identity and anti-gay social stigma (Meyer, 1995). Lastly, internalized homophobia is the internalization of social negativity toward homosexuality at the initial stages of an individual's identity development which may continue throughout the life course (Meyer, 1995). While MST has been applied to other populations including women, immigrants, the impoverished and racial/ethnic minorities (Meyer, 2003), few studies have applied the theory to sexual minority populations (Meyer et al., 2008) including gay and bisexual men. Such application of theoretical understanding of risk behavior may hold major implications for HIV and substance use interventions among gay and bisexual men.

Aspects of minority stress, including the perception of prejudice, stigma or rejection, may be correlated with depression and avoidant coping strategies (Courtenay-Quirk et al., 2006). Preston, D’Augelli, Kassab and Starks (2007) found greater likelihood of sexual risk behavior among those with higher rates of perceived stigma and expectations of rejection from their community, along with others that have examined the impact of health and mental health issues among gay and bisexual men related to substance use and sexual risk behavior (Cochran, Mays \& Sullivan, 2003; Mays \& Cochran, 2001). However, continued research is needed to clarify the effects of both perceived and actualized experiences of victimization, discrimination and harassment with sexual risk behaviors (Mustanski, Newcomb, Du Bois et al., 2011) among gay and bisexual men, in order to provide interventions that are maximally effective. Ongoing 
evaluation is necessary with regard to the implications of theory and how sociodemographic factors (Dohrenwend et al., 1992) may impact the engagement of risk behaviors among gay and bisexual men.

To complement existing analyses of substance use and sexual risk behavior among gay and bisexual men, this secondary data analysis explores such behaviors, correlations with MST and additional factors including partner type, HIV status, age, race/ethnicity, education and employment status. Implications for HIV and substance use interventions, clinical practice and ongoing research are explored to address gaps in knowledge related to appropriate and effective interventions (Natale \& Moxley, 2009) and theoretical approaches for understanding risk behavior (Hamilton \& Mahalik, 2009; Halkitis, Palamar \& Mukherjee, 2007).

Aims of the present study were: (1) to examine and test reliability of variables constructed to represent minority stress factors including external prejudice, expectations of rejection and internalized homophobia; and (2) to evaluate the relationship between minority stress factors, unprotected insertive anal intercourse (UIAI) and/or unprotected receptive anal intercourse (URAI) among gay and bisexual men with primary and non-primary partners, whether on drugs or not on drugs at the time of occurrence. In this study, we hypothesize that minority stress factors (external prejudice, expectations of rejection, internalized homophobia) will increase likelihood of risk associated with unprotected insertive and receptive anal intercourse among gay and bisexual men with primary and non-primary partners, whether on drugs or not on drugs, at the time of occurrence.

\section{$\underline{\text { Methods }}$}

Baseline data was analyzed from Club Drug Use and Men's Health: A Community Study (Project BUMPS), a National Institute on Drug Abuse funded longitudinal study of gay and 
bisexual men $(\mathrm{N}=450)$ in New York City who use club drugs, defined as cocaine, ecstasy, ketamine, methamphetamine, and gammahydroxybutrate (Halkitis, Green \& Mourgues, 2005). Subjects were recruited from bars, clubs, and bathhouses using both active (i.e. handing out palm cards) and passive (i.e. posting flyers) methods (Halkitis, Green \& Mourgues, 2005). Eligibility requirements included: (1) 18 years of age or older, (2) self identification as gay or bisexual, and (3) self-report at least six instances of club drug use within the past year, with a minimum of one instance of use in combination with sex in the three months prior to screening (Halkitis, Green \& Mourgues, 2005). After informed consent and confirmation of HIV status, baseline interviews were conducted and participants were compensated for time and travel at the end of each assessment with an escalating monetary incentive (Halkitis, Palamar \& Mukherjee, 2007). Data was collected from February 2001 until October of 2002 throughout the five boroughs of New York City. Additional details related to study recruitment and compensation have been described elsewhere (Halkitis, Mukherjee \& Palamar, 2007; Halkitis, Palamar \& Mukherjee 2007; Halkitis, Green \& Mourgues, 2005). Final approval from the Institutional Review Board of the institution associated with the present analysis determined exempt status from the IRB oversight requirement according to 45 CFR 46.101 on April 5, 2011.

Dependent Variables: Substance use and sexual risk behavior were defined by at least one use of a club drug and at least one occasion of sexual risk behavior in the four months prior to the baseline interview. Based on previous literature, such frequencies of behavior represented consistent patterns of usage among similar urban MSM samples (Halkitis, Mukherjee, Palamar, 2008; Halkitis \& Parsons, 2002; Klitzman et al., 2000).

Substance use was assessed on a five point scale ranging from (0) never, (1) less than once a month, (2) one to two times a month, (3) one to two times a week, (4) more than twice a 
week, with regard to the question: "In the last four months, how often have you used..."

followed by each of the five club drugs examined: methamphetamine, ecstasy, ketamine, cocaine or GHB. An affirmative response to at least one time usage of one of the five club drugs in the four months prior to baseline signified substance use. Variables were dichotomized to indicate "use" or "no use" at the time of sexual risk behavior over the last four months.

Sexual risk behavior was assessed by asking the number of times the participant engaged in either insertive or receptive anal sex with a primary or non-primary partner of sero-negative, sero-positive or sero-unknown status in the past four months. Non-primary partners were defined as "tricks, one-night stands and fuck buddies" (Halkitis, Green \& Mourgues, 2005).

Four dichotomous variables were initially computed for each category type of sexual risk behavior: (1) unprotected insertive anal intercourse with primary partner (UIAI-P); (2) unprotected receptive anal intercourse with primary partner (URAI-P); (3) unprotected insertive anal intercourse with non-primary partner (UIAI-NP); (4) unprotected receptive anal intercourse with non-primary partner (URAI-NP). The variable assessing UIAI-P and URAI-P was collapsed (UAI) to include both insertive and receptive anal intercourse with primary partner for a stronger sample size $(n=131)$. Variables computed for unprotected receptive anal intercourse (URAI) with non-primary partner $(\mathrm{n}=184)$; and unprotected insertive anal intercourse UIAI with non-primary partner $(\mathrm{n}=173)$ were not collapsed. Each variable contained all three partner types: sero-negative, sero-positive and unknown status, whether with primary or non-primary partner. An affirmative response to at least one occasion in which a respondent engaged in unprotected insertive or receptive anal sex with primary or non-primary partner, while on drugs or while not on drugs, signified the level and type of sexual risk behavior. Receptive anal intercourse, 
whether with primary or non-primary partner while on drugs at the time of occurrence was assumed to predict the greatest potential for risk.

Independent Variables: Independent variables were developed using minority stress theory (Meyer, 1995, 2003) and included items related to external prejudice, expectations of rejection and internalized homophobia. For each minority stress variable, the mean score for all items in that variable was calculated. Variables were dichotomized as "yes" when participants responded to categories four or five, "agree" or "strongly agree". Reliability for each was checked using Cronbach’s Alpha.

External prejudice was assessed using a series of questions taken from the Internalized Homophobia Scale (Reaction to Homosexuality Scale D Revised; Ross \& Rosser, 1996). The Reaction to Homosexuality Scale D was developed as a multidimensional scale to measure feelings of internalized homophobia among MSM, comprised of items derived from theoretical and clinical reports of internalized homophobia suggesting that the clinical construct is measurable and psychometrically has both internal reliability and concurrent validity (Ross \& Rosser, 1996). Previous research has indicated that the scale has acceptable internal consistency and correlated as expected with relevant measures (Herek, et al. 1997).

Experiences of prejudice were scored on a five point scale ranging from: (1) strongly disagree, (2) disagree, (3) neither disagree or agree, (4) agree, to (5) strongly agree, while reponding to the following four statements: "Most people have negative reactions to homosexuality", "Society still punishes people for being gay", "Only a few people discriminate against gay men" and "Discrimination against gay people is still common".

Expectations of rejection was assessed using a series of questions taken from the Sense of Belonging Index (Sense of Belonging Index; Hagerty \& Patusky, 1995) and the Internalized 
Homophobia Scale (Reaction to Homosexuality Scale D Revised; Ross \& Rosser, 1996). Using the same five point scale ranging from (1) strongly disagree to (5) strongly agree, participants responded to: "It is harder in life to be a gay man than a straight man", "Making an advance to another man is difficult for me", and "I would like to make a difference to people or things around me but I don't feel that what I have to offer is valued"

Internalized homophobia was assessed by responses to a series of questions taken from the Internalized Homophobia Scale (Reaction to Homosexuality Scale D Revised; Ross \& Rosser, 1996) including: "Social situations with gay men make me feel uncomfortable", "I avoid thinking about my homosexuality/bisexuality", "When I think about other gay men, I think of negative situations", "It is important to me to control who knows about my homosexuality/ bisexuality" and "I would prefer to be more heterosexual". Additionally, questions were taken from the Lesbian and Gay Identity Scale (Mohr \& Fassinger, 2000): “Admitting to myself that I'm a gay/bisexual man has been a very painful process" and the Conceptualization of Masculinity Scale (Halkitis, Green \& Wilton, 2004): "I watch my behavior to make sure that I act masculine around other gay men" and "I am not comfortable around non-masculine gay men”. Participants responded to all questions for this variable using the same 5-point scale ranging from (1) strongly disagree to (5) strongly agree.

A dichotomous variable was computed for each sociodemographic factor. Participants self reported age: (18-24, 25-67); educational level: (no bachelor's degree, bachelor's degree or higher); racial/ethnic identification: (non-white, white) and employment status: (unemployed, employed). Participants self reported HIV positive status; HIV testing was conducted for those with unknown or HIV negative status (HIV negative, HIV positive). The age variable was dichotomized to examine differences regarding sexual risk behavior among younger and older 
cohorts, as well as to assess any correlation with trends demonstrating a significant increase in new HIV diagnoses among the 18-24 year old cohort. Racial/ethnic identification was dichotomized as the majority of the sample identified as White $(n=230)$, while collapsing the non-White categories increased the sample size $(n=220)$ for comparison. The non-White categories included: African American/Black, Hispanic/Latino, Asian/Pacific Islander and Mixed Race.

The sample consisted of 396 gay and 54 bisexual men $(N=450)$ with a mean age of 33 years old $(\mathrm{SD}=7.93$, range $18-67)$ (Table 1$)$. Respondents identified their racial/ethnic background as White (51.1\%) or Non-White (48.9\%) including African American/Black, Hispanic/Latino and Asian/Pacific Islander \& Mixed Race. The majority of respondents (51.4\%) had a bachelor's degree or higher and 48.6\% had no bachelor's degree. Most of the respondents were employed full-time or part-time $(60.9 \%)$ and $38.9 \%$ were unemployed, including those on disability. The majority of respondents were HIV negative $(63.1 \%)$, while $36.9 \%$ were HIV positive. Among the sample participants, frequencies for one time drug use included: crystal methamphetamine (87\%); ecstasy (86\%); ketamine (90\%); GHB (97\%) and cocaine (66\%) (Halkitis, Green \& Mourgues, 2005).

$\underline{\text { Analysis }}$

To test the internal consistency and reliability of each minority stress factor, Cronbach alpha analysis was conducted and means scores calculated. Correlation among all three minority stress factors were between .24 and .43 , suggesting collinearity was likely not a problem for this model. Multivariable logistic regression analysis was used to examine the association of each minority stress factor and engaging in risk behaviors (unprotected insertive or receptive anal intercourse with primary or non-primary partner whether on drugs or not on drugs) while 
controlling for demographic characteristics (age, race/ethnicity, education, employment, and HIV status). Odds ratios were calculated using $95 \%$ confidence intervals.

$\underline{\text { Results }}$

Minority Stress Factors: Results from the examination and reliability testing of variables constructed to represent minority stress factors, including external prejudice, expectations of rejection, and internalized homophobia, follows. The number of respondents missing values for the expectation of rejection and internalized homophobia variables was less than ten percent and therefore these cases were dropped resulting in the following sample size for each stress factor: external prejudice $(n=450)$; expectations of rejection $(n=443)$ and internalized homophobia $(n=443)$. Reliability for each stress factor using Cronbach's Alpha demonstrated the following results: external prejudice ( $\alpha=0.65)$; expectations of rejection $(\alpha=0.40)$; and internalized homophobia $(\alpha=0.74)$. The alpha for expectations of rejection was lower than expected $(\alpha=$ 0.40) thus demonstrating a lack of internal consistency and reliability. Means (M) and standard deviation (SD) for each minority stress factors follow (M, SD): external prejudice $(2.29,0.63)$; expectations of rejection $(2.83,0.75)$; and internalized homophobia $(2.25,0.65)$.

Multivariable Models: Association of Minority Stress with Sexual Risk Behavior \& Drug Use by Partner Type

Unprotected Anal Intercourse with Primary Partner: The relationship between minority stress factors, sociodemographics and unprotected anal intercourse (UAI) with primary partner are displayed in Table 2. After controlling for sociodemographics including HIV status, older age (25-67) approached signifiance with lower odds of UAI with primary partner than younger participants (AOR 0.97), (95\% CI: .94, 1.00). Similarly, participants reporting stronger 
associations with experiences related to expectations of rejection had lower odds of engaging in UAI with their primary partners (AOR 0.70), (95\% CI: .50, 0.97).

Unprotected Insertive Anal Intercourse (UIAI) with Non-Primary Partners: Participants reporting stronger associations with experiences related to expectations of rejection (Table 3 ) had lower odds of engaging in UIAI while on drugs (AOR 0.56), (95\% CI: .38, 0.81) and while not on drugs (AOR 0.54), (95\% CI: .36, 0.80) with non-primary partners. There was no other significant association with remaining stress factors or sociodemographics.

Unprotected Receptive Anal Intercourse (URAI) with Non-Primary Partners: Older age approached signifiance with a lower odds of URAI both while on drugs (AOR 0.97), (95\% CI: $.93,1.00)$ and while not on drugs (AOR 0.96), (95\% CI: .92, 0.99) with non-primary partners than among younger study respondents (Table 4). There was no other significant association with remaining stress factors or sociodemographics.

\section{$\underline{\text { Discussion }}$}

This study examined minority stress factors associated with sexual risk behavior and substance use related to UIAI and URAI among gay and bisexual men with primary or nonprimary partners while on drugs or not on drugs at the time of occurrence. The study was unique in several ways. First, minority stress theory has not been tested among gay and bisexual men with relation to risk behaviors including club drug use and sexual risk with primary and nonprimary partners. Such research lends to the important role of examining theoretical origins for behavior while underscoring the need for continued study of minority stress factors among gay and bisexual men, and whether such stressors act as risk or protective factors for drug use and sexual risk behavior. As indicated by previous studies, theoretical origins of risk behavior provides concrete evidence of the deleterious implications related to perceived and experienced 
stressors such as victimization through crime (Herek, 2007; Herek, Gillis \& Cogan, 1999) nondisclosure of HIV status (Halkitis \& Parsons, 2003) "bareback" or unprotected sex (CourtenayQuirk, Wolitski, Parsons et al., 2006; Halkitis, Zade, Shrem et al., 2004) drug use and experimentation (Marshal, Friedman, Stall et al., 2008; Hirshfield, Remien, Humberstone et al., 2004) and sex with multiple partners (Parsons, Severino, Nanin et al., 2006). This exploratory analysis provides a framework for continued research surrounding development of a study design and research instruments to support the theoretical construct of minority stress as part of an explanatory model for risk behavior among gay and bisexual men.

Minority Stress, Partner Type \& Risk: This research study found no collective or consistent association among the three minority stress factors, substance use and type of sexual risk behavior. Regardless of partner type, it was expected that the odds would exponentially increase for substance use and sexual risk behavior among study participants who reported an association with all of the minority stress factors. The minority stress factor related to expectations of rejection was associated with lower odds of engaging in UAI with primary partner, as well as UIAI with non-primary partners. However, this variable had the least internal consistency and reliability. Therefore, what was initially believed to be a potential risk factor for increasing likelihood of sexual risk behavior among study participants, resulting in the perception of a protective factor for not engaging in such behaviors, remains questionable. The overall impact of those who had feelings associated with expectations of rejection acting as a protective factor for not engaging in UIAI and URAI requires further study. A more comprehensive examination of minority stress factors and correlations with partner and risk type is strongly recommended to expand knowledge in this area as well as implications for the field. 
Older Age: While not substantial, the finding specific to the role of older age as a potential protective factor for engaging in less risky sexual behavior among the sample population may underscore ongoing challenges with reducing increased rates of HIV incidence among younger gay and bisexual men. Sixty-eight percent of all U.S. cases of HIV infection among all young people ages 13-24 were among young men who have sex with men (YMSM) (CDC, 2010b). However, there remains a significant difference with age and race as most new infections occur among 13-29 year olds, with more Black YMSM in this age group becoming infected than any other age and racial group (CDC, 2010a). Another critical factor to consider is the limited, yet ongoing research evaluating associations between primary and non-primary partner, age and type of sexual risk behaviors. Some studies demonstrate a positive association with YMSM that have older sexual partners and increased potential for sexual risk behaviors (Bingham, Harawa, Johnson et al., 2003; Morris, Zavisca \& Dean, 1995).

Limitations: The time frame of the study may illustrate a potential limitation related to generalizing results to the present day. However, gay and bisexual men continue to confront a wide range of stressors from the legal to social levels (Herek \& Garnets, 2007). Although these minority stress factors may have been assessed at a different point in time, it is evident that they have not abated with ongoing challenges such as legalizing marriage, immigration policy, hospital visitation rights, estate planning and adoption barriers. Participants solely consisted of club drug users, therefore comparisons of such findings with non-drug users was not possible. Accuracy of self-reported drug use and type of sexual risk behavior is potentially a limitation due to challenges with recall of a poly-substance induced state. Use of an urban sample of predominantly white subjects is another limitation, as well as the self-selected sample (Halkitis, Palamar \& Mukherjee, 2007) and self-report of one instance of sex with drug use prior to 
baseline. Dichotomizing age into two distinct categories may have limited a more comprehensive analysis of risk factors across smaller age cohorts. Furthermore, study participants categorized as non-White were not sufficiently represented in unique categories to allow for a more thorough examination of specific race/ethnicity differences. Limitations surrounding sample selection include the fact that the initial study did not intend to examine the role of minority stress. The definition of minority stress is limited to those questions examined in this study and may not fully define or explain a more robust understanding of external prejudice, expectations of rejection and internalized homophobia. This specifically may have impacted the significance of the variable for expectations of rejection, which demonstrated a lack of internal consistency and reliability, providing yet another study limitation. Utilization of the complete scales to assess minority stress factors may have resulted in alternative outcomes, and future analysis might include more comprehensive variables not present in this study. Lastly, an ongoing challenge for this and future studies surrounds the inconsistent use of definitions and terms within the wider literature, such as associations with the term MSM (Mustanski, Newcomb, Du Bois et al., 2011); club drug categories and street names (Halkitis et al., 2005); subculture associations such as bareback sex; and with regard to social settings (i.e. gay bathhouse) in which risk behavior occurs.

$\underline{\text { Conclusions }}$

Gay and bisexual men who have previously experienced prejudice, rejection, stigma or other anticipation of such events may have developed a significant amount of vigilance (Meyer 2003), underscoring protective factors such as coping, adaptation and resilience. This may be compared to other individuals who cope with general stress, in that gay and bisexual men use a range of personal coping mechanisms and hardiness to withstand stressful experiences (Masten, 
2001; Ouellette, 1993; Antonovsky, 1987). Vigilance must be maintained consistently to counter any negative regard, discrimination, and or potential for violence. Crocker et al. (1998) described this as the "need to be constantly 'on guard' $[\ldots]$ alert, or mindful of the possibility that the other person is prejudiced" (p. 517). Such behaviors and experiences may increase an individual's adaptability or ability to cope, while also facilitating protective factors to be utilized during stressful situations.

Minority identity is linked to a variety of stress processes; some gay and bisexual men may be vigilant in interactions with others and anticipate expectations of rejection, while others may hide or conceal their identity for fear of harm, while others may internalize homophobia and stigma (Postmes \& Branscombe, 2002). Ultimately, minority status may be associated not only with stress but with important resources such as group solidarity and cohesiveness that protect gay and bisexual men from the adverse mental health effects of minority stress (Postmes \& Branscombe, 2002; Branscombe, Schmitt, \& Harvey, 1999; Clark, Anderson, Clark, et al., 1999). This research study suggests the possibility that experiences of rejection may have an association with protective factors that correlate with decreased odds for substance use and sexual risk behaviors among gay and bisexual men. Continued examination related to the role of developing coping and resilience mechanisms, along with assessment of increased vigilance among gay and bisexual men who are actively engaging in substance use and sexual risk behaviors is necessary. Ongoing study and subsequent findings may lead researchers, clinicians and policy makers to further investigate the vital role of stress theory and individual level determinants for sexual risk behavior and substance use among sexual minority communities. Such findings may additionally assist with a greater understanding of the impact of group and community level determinants of risk and/or factors associated with social causation. 
Research in this area may stimulate progressive changes in HIV prevention and substance use treatment and education efforts among gay and bisexual men. Further, offering new conceptualizations of risk behavior and attitudes may impact effective clinical practice methods and standards while working with these communities. There remains an ongoing need for more effective outreach and interventions targeting younger and racial/ethnic minority populations as trends related to increased HIV incidence continue to rise. Ultimately, direct experiences of stressors or feelings associated with minority stress among gay and bisexual men may not solely be responsible for ongoing substance use or sexual risk behavior regardless of partner type. Both practitioners and researchers alike should continue the examination of co-occurring matters that impact such behaviors.

\section{$\underline{\text { References }}$}

Antonovsky, A. (1987). Unraveling the mystery of health: How people manage stress and stay well. San Francisco: Jossey-Bass.

Bimbi, D. S., Nanin, J. E., Parsons, J. T., Vicioso, K. J., Missildine, W. \& Frost, D. (2006). Assessing gay and bisexual men's outcome expectancies for sexual risk under the influence of alcohol and drugs. Substance Use \& Misuse, 41, 643-652.

Bingham, T. A., Harawa, N. T., Johnson, D. F., Secura, G. M., MacKellar, D. A. \& Valleroy, L. A. (2003). The effect of partner characteristics on HIV infection among African American men who have sex with men in the Young Men's Survey, Los Angeles, 19992000. AIDS Education and Prevention, 15, 39-52.

Branscombe, N. R., Schmitt, M. T., \& Harvey, R. (1999). Perceiving pervasive discrimination among African Americans: Implications for group identification and well-being. Journal of Personality and Social Psychology, 77, 135-149. 
Centers for Disease Control and Prevention (2010a). HIV and AIDS among gay and bisexual men. Atlanta, GA: U.S. Department of Health and Human Services.

Centers for Disease Control and Prevention (2010b). HIV surveillance in adolescents and young adults. Atlanta, GA: U.S. Department of Health and Human Services.

Clark, R., Anderson, N. B., Clark, V. R., \& Williams, D. R. (1999). Racism as a stressor for African Americans: A biopsychosocial model. American Psychologist, 54, 805-816.

Cochran, S. D., Mays, V. M. \& Sullivan, J. G. (2003). Prevalence of mental disorders, psychological distress, and mental health services use among lesbian, gay and bisexual adults in the United States. Journal of Consultation in Clinical Psychology, 71, 1, 53-61.

Courtenay-Quirk, C., Wolitski, R. J., Parsons, J. T., Gomez, C. A., \& Seropositive Urban Men’s Study Team. (2006). Is HIV/AIDS stigma dividing the gay community? Perceptions of HIV-positive men who have sex with men. AIDS Education and Prevention, 18, 1, 5667.

Crocker, J., Major, B. \& Steele, C. (1998). Social stigma. In D. Gilbert, S. T. Fiske \& G. Lindzey (Eds.). The handbook of social psychology (4 ${ }^{\text {th }}$ Ed.), 504-553. Boston: McGraw-Hill.

Dohrenwend, B. P., Levav, I., Shrout, P., Schwartz, S., Nahev, G., et al. (1992). Socioeconomic status and psychiatric disorders: The causation-selection issue. Science, 255, 946-952.

Hagerty, B. M. \& Patusky, K. (1995). Developing a Measure of Sense of Belonging. Nursing Research, 44, 1, 9-13.

Halkitis, P. N., Green, K. A., Carragher, D. J. (2006). Methamphetamine Use, Sexual Behavior and HIV Seroconversion. Journal of Gay \& Lesbian Psychotherapy, 10, 3/4.

Halkitis, P. N., Green, K. A. \& Mourgues, P. (2005). Longitudinal investigation of methamphetamine use among gay and bisexual men in New York City: Findings from 
project bumps. Journal of Urban Health: Bulletin of the New York Academy of Medicine, $82,1,18-25$.

Halkitis, P. N., Green, K. A. \& Wilton, L. (2004). Masculinity, body image, and sexual behavior in HIV-seropositive gay men: A two-phase formative behavioral investigation using the internet. International Journal of Men's Health, 3, 1, 27-42.

Halkitis, P. N., Mukherjee, P. P., \& Palamar, J. J. (2008). Longitudinal modeling of methamphetamine use and sexual risk behaviors in gay and bisexual men. AIDS Behavior.

Halkitis, P. N., Palamar, J. J., \& Mukherjee, P. P. (2007). Poly-club-drug use among gay and bisexual men: A longitudinal analysis. Drug and Alcohol Dependence, 89, 153-160.

Halkitis, P. N. \& Parsons, J. T. (2003). Intentional unsafe sex (barebacking) among HIV-positive gay men who seek sexual partners on the internet. AIDS Care, 15, 3, 367-378.

Halkitis, P. N., Parsons, J. T. (2002). Recreational drug use and HIV-risk sexual behavior among men frequenting gay social venues. Journal of Gay \& Lesbian Social Services, 14, 19-38.

Halkitis, P. N., Zade, D. D., Shrem, M. \& Marmor, M. (2004). Beliefs about HIV non-infection and risky sexual behavior among MSM. AIDS Education \& Prevention, 16, 5, 448-458.

Hamilton, C. J. \& Mahalik, J. R. (2009). Minority stress, masculinity, and social norms predicting gay men's health risk behaviors. Journal of Counseling Psychology, 56, 1, $132-141$.

Herek, G. M. \& Garnets, L. D. (2007). Sexual Orientation and mental health. Annual Review of Clinical Psychology, 3, 353-375. 
Herek, G. M., Gillis, J. R. \& Cogan, J. C. (1999). Psychological sequelae of hate-crime victimization among lesbian, gay, and bisexual adults. Journal of Consulting and Clinical Psychology, 67, 945-951.

Herek, G. M., Cogan, J. C., Gillis, J. R. \& Glunt, E. K. (1997). Correlates of internalized homophobia in a community sample of lesbians and gay men. Journal of the Gay and Lesbian Medical Association, 2, 17-25.

Hirshfield, S., Remien, R. H., Humberstone, M., Walavalkar, I. \& Chiasson, M. A. (2004). Substance use and high-risk sex among men who have sex with men: A national online study in the USA. AIDS Care, 16, 8, 1046-1047.

Jerome, R. C., Halkitis, P. N. \& Siconolfi, D. S. (2009). Club drug use, sexual behavior, and HIV seroconversion: A qualitative study of motivations. Substance Use \& Misuse, 44, 303 319.

Kalichman, S. C., \& Cain, D. (2004). A prospective study of sensation seeking and alcohol use as predictors of sexual risk behaviors among men and women receiving sexually transmitted infection clinic services. Psychology of Addictive Behaviors: Journal of the Society of Psychologists in Addictive Behaviors, 18, 4, 367-373.

Kashubeck-West, S., \& Szymanski, D. M. (2008). Risky sexual behavior in gay and bisexual men: Internalized heterosexism, sensation seeking, and substance use. The Counseling Psychologist 36, 4, 595-614.

Klitzman, R. L., Pope, H. G., Hudson, J .I. (2000). MDMA (“Ecstasy”) abuse and high-risk sexual behaviors among 169 gay and bisexual men. American Journal of Psychiatry, 157, 1162-1164. 
Link, B. G. \& Phelan, J. C. (2006). Stigma and its public health implications. Lancet, 367, 528529.

Marshal, M. P., Friedman, M. S., Stall, R., Kling, K. M., Miles, J., et al. (2008) Sexual orientation and adolescent substance use: A meta-analysis and methodological review. Addiction, 103, 546-556.

Masten, A. S. (2001). Ordinary magic: Resilience processes in development. American Psychologist, 56, 227-238.

Mays, V. M., \& Cochran, S. D., (2001). Mental health correlates of perceived discrimination among lesbian, gay, and bisexual adults in the United States. American Journal of Public Health, 91(11), 1869-1876.

McKirnan, D. J., Ostrow, D. G., \& Hope, B. (1996). Sex, drugs and escape: A psychological model of HIV-risk sexual behaviors. AIDS Care, 8, 6, 655-669.

Meyer, I. H., Schwartz, S. \& Frost, D. M. (2008). Social patterning of stress and coping: Does disadvantaged social statuses confer more stress and fewer coping resources? Social Science \& Medicine, 67, 368-379.

Meyer, I. H. (2003). Prejudice, social stress, and mental health in lesbian, gay and bisexual populations: Conceptual issues and research evidence. Psychological Bulletin, 129, 674697.

Meyer, I. H. (1995). Minority stress and mental health in gay men. Journal of Health and Social Behavior, 36, March, 38-56.

Mohr, J. \& Fassinger, R. (2000). Measuring dimensions of lesbian and gay male experience. Measurement and Evaluation in Counseling and Development, 33, 66-88. 
Morris, M., Zavisca, J. \& Dean, L. (1995). Social and sexual networks: Their role in the spread of HIV/AIDS among young gay men. AIDS Education and Prevention, 7, 24-35.

Mustanski, B. S., Newcomb, M. E., Du Bois, S. N., Garcia, S. C., Grov, C. (2011). HIV in Young Men Who Have Sex with Men: A Review of Epidemiology, Risk and Protective Factors, and Interventions. Journal of Sex Research, 48(2-3), 218-253.

Natale, A. P. \& Moxley, D. P. (2009). Service engagement with high-risk men who have sex with men: Challenges and implications for social work practice. Social Work in Health Care, $48,38-56$.

Ouellette, S. C. (1993). Inquiries into hardiness. In L. Goldberger \& S. Breznitz (Eds.). Handbook of stress: Theoretical and clinical aspects ( $2^{\text {nd }}$ ed. $), 77-100$. New York: Free Press.

Parsons, J. T., Severino, J., Nanin, J., Punzalan, J. P., von Sternberg, K., Missildine, W. \& Frost, D. (2006). Positive, negative, unknown: Assumptions of HIV status among HIV-positive men who have sex with men. AIDS Education and Prevention, 18, 2, 139-149.

Preston, D. B., D'Augelli, A. R., Kassab, C. D. \& Starks, M. T. (2007). AIDS Education \& Prevention, 19, 3, 218-230.

Postmes, T., \& Branscombe, N. R. (2002). Influence of long-term racial environmental composition on subjective well-being in African Americans. Journal of Personality and Social Psychology, 83, 735-751.

Ross, M. W. \& Rosser, B. R. (1996). Measurement and correlates of internalized homophobia: A factor analytic study. Journal of Clinical Psychology, 52, 1, 15-20.

Weinstein, N. D. (1993). Testing four competing theories of health-protective behavior. Health Psychology, 12, 324-333. 